\title{
Informal input suppliers, quality choice and welfare
}

\author{
Sergio Daga ${ }^{1} \cdot$ Pedro Mendi ${ }^{2}$
}

Received: 11 December 2019/Accepted: 13 December 2021 / Published online: 31 December 2021

(C) The Author(s) 2021

\begin{abstract}
This paper proposes a theoretical model in which a formal upstream firm competes against informal input suppliers, which constitute an alternative, albeit lower-quality input source for formal downstream firms. The existence of an alternative source increases competition in the industry, which tends to be welfare-increasing. However, it may also distort the incentives of the formal upstream firm to invest in quality upgrading. Assuming quantity competition downstream, we analyze how these incentives change and whether the negative welfare effect of a reduced investment by the upstream firm may more than offset the positive welfare effect of increased competition brought about by informal input suppliers. We find that there are parameter values such that this is the case, and welfare decreases if informal input suppliers are present. We analyze the robustness of this result to alternative modeling assumptions, such as price competition downstream and the use of twopart tariffs by the formal upstream firm.
\end{abstract}

Keywords Informal sector · Product differentiation - Supply chain - Welfare economics

JEL Classification D60 - L13 · L14 · O17

Pedro Mendi

pmendi@unav.es

Sergio Daga

sergiodaga@upsa.edu.bo

1 Universidad Privada de Santa Cruz de la Sierra. Av. Paraguá y Cuarto Anillo,

Santa Cruz de la Sierra, Bolivia

2 Department of Business, Edificio Amigos, University of Navarra, Pamplona 31009, Spain 


\section{Introduction}

A common feature of many developing countries is the existence of a large informal sector, which accounts for a significant percentage of the total economic activity and employment in these countries. Formal firms have to compete not only against other formal firms, but also against firms in the informal sector. This certainly increases the level of competition, which may have a positive effect on welfare. However, at the same time, the presence of informal firms may alter formal firms' incentives to carry out investments (Mendi and Costamagna 2017), which may negatively affect welfare. Therefore, we may a priori identify a positive effect on welfare of the presence of informal firms, through increased competition, and a potentially negative effect, via a distortion of formal firms' incentives to invest.

In this paper, we analyze this issue by considering a model of an industry with an upstream and a downstream sector. There are two formal firms downstream and a formal firm upstream. We allow for the possibility of the formal upstream firm competing with informal firms to sell a lower-quality input to the downstream firm, and we assume that the informal sector is perfectly competitive. We use the model to analyze how the existence of informality upstream, and more generally, an alternative, competitive, lower-quality input source, affects the incentives of the upstream firm to engage in quality upgrading and its welfare implications. Specifically, while the presence of informal input suppliers increases competition in the downstream industry, it may also distort the upstream firm's incentives to invest in quality upgrading. We find that there are parameter values such that welfare decreases with informal input suppliers. This result holds for both quantity and price competition, but does not arise if the upstream firm may impose two-part tariffs.

In our model the fundamental difference between the inputs sold by formal and informal suppliers is quality. We assume that informal input suppliers are a competitive fringe that sell a lower-quality substitute for the formal upstream firm's input. We also allow downstream firms to have different transformation capacities, which could give rise to vertical differentiation in the final product even though there is no differentiation in the inputs that they use. Therefore, in our model, vertical differentiation arises from purchasing inputs with different qualities, or from the fact that downstream firms have different transformation capacities. In the presence of consumers with heterogeneous willingness to pay for quality, higher willingness-to-pay consumers will purchase the high-quality product, whereas consumers with lower willingness to pay will purchase the low-quality product, and some others will not purchase at all.

We find that the results depend on the industry structure downstream, as well as on the transformation capacities of the downstream firms. In particular, if there is a monopoly downstream or two symmetric firms downstream, the presence of informal input suppliers always increases the incentives to invest on the side of the upstream firm and is welfare-increasing. However, when there is an asymmetric duopoly downstream, then the upstream firm's incentives to invest may be greater in the absence of informal input suppliers, which could more than offset the positive effect on welfare of the presence of informal input suppliers, via enhanced 
competition. This is the case when the asymmetry is high enough so that in the absence of informal input suppliers the upstream firms manages to sell its input to both firms, whereas it only sells to the most efficient downstream firm in the presence of informality upstream in the value chain.

The remainder of the paper is organized as follows. Section 2 discusses the contributions to the literature that are relevant for our analysis. Sects. 3 and 4 study the cases of a downstream monopoly and duopoly, respectively. Sect. 5 extends the analysis to the cases of price competition downstream and two-part tariffs, and Sect. 6 presents the conclusions of the study.

\section{Literature review}

Informality has long been an object of study in the literature. Informality is a term used to describe the collection of firms, workers, and activities that operate outside the legal and regulatory frameworks or outside the modern economy (Loayza 2016). There are at least three major views of the informal sector. First, informal firms are seen as an untapped reservoir of entrepreneurial energy held back by government regulations, and poor protection of property rights (De Soto 1989, 2000). Under this view, relaxing these burdens would more likely bring growth and development. Second, informal firms are parasites competing unfairly with law-abiding formal firms (Farrell 2004). This view could be interpreted as that informal firms should not be helped, but suppressed. Third, formal and informal firms are fundamentally different (La Porta and Shleifer 2014). On one hand, formal firms are more likely run by educated entrepreneurs, comply with taxes and regulations, reach new consumers, are less financially constrained, and their business are more profitable. On the other hand, informal firms are more likely run by people less educated and unproductive, their output is of low-quality and reach mostly low-income consumers.

The informal sector should be thought of as one whose output overlaps and competes with that from the formal sector. In fact, given the potential consequences of the informal economy on firms management decisions, McGahan (2012) argues that formal and informal firms should be studied together, since, in some circumstances, they might compete with formal firms for the same customers and resources. There is nevertheless a "quality gap" between outputs of the two sectors. This difference in quality can be traced to the different factor prices faced in production, and to the heterogeneity of consumers' preferences. Since informal firms have a more difficult access to capital, technology, and skilled labor, it is reasonable to think that informal firms will produce products whose level of quality would be lower than those produced by formal firms. For instance, Banerji and Jain (2007) claim that there is a great deal of support for the stylized fact that informal sector's output competes with, and is a substitute for, the output of the formal sector.

Vertical differentiation is the modeling approach that we adopt to reflect quality differences, and in our model it appears as a consequence of using input of different qualities as well as to different transformation capacities downstream. This contrasts with other reasons for the existence of vertical differentiation, such as minimum 
quality standards (Valletti 2000), import tariffs (Herguera et al. 2002), or subsidies (Jinji 2003). In the modeling dimension, our paper is closely related to the work of Avenel and Caprice (2006). They also analyze a model of vertical differentiation in which retailers compete in quantities and in the choice of product lines and may purchase a high quality good from a monopolist manufacturer. As in our model, the low quality good is produced by a competitive fringe. Depending on quality and cost differentials, the product lines chosen by retailers in equilibrium are either identical, completely different or partially overlapping. In their model, in the absence of upstream market power, the unique equilibrium is for retailers to offer identical product lines. In our model downstream firms have different transformation capacities, thus leading to vertical differentiation even in the absence of a competitive alternative source. In related contributions, Moner-Colonques et al. (2004) propose a model of choice of distribution channels, namely strategic delegation by a multiproduct firm, and Milliou and Sandonís (2018) find that an upstream merger, but not vertical integration, increases product variety.

Our model features a quality-upgrading decision, which has been the object of study in the literature. Motta (1993) analyzes the incentives to invest in quality upgrading for the cases of price and quantity competition. Liu (2016) proposes a model where investment in innovation takes place both upstream and downstream. Brécard (2010) argues that the introduction of a unit production cost first reduces and then increases product differentiation and prices in a vertical differentiation model with fixed costs for quality improvement. Mendi (2015) studies the qualityupgrading decision of a firm that competes against a fringe of producers of a lowerquality product to find that there are parameter values such that the relationship between innovation incentives and competition, measured by the difference in quality levels, has an inverted-U shape.

This quality-upgrading decision may also be regarded as a innovation investment by the upstream firm, which may be affected by the presence of informal competitors (Mendi and Costamagna 2017). This way, our paper is also related to the literature that connects competitive pressure and incentives to innovate (Arrow 1962). Theoretical predictions and empirical evidence on this regard are mixed: while competitive pressure induces the firm to further differentiate (escape competition effect), on the other hand, it reduces the return from innovation (rent-dissipation effect). Vives (2008) shows that the theoretical results are very sensitive to the modeling assumptions, and Aghion et al. (2005) find empirically that there exists an inverted U-shaped relationship between product market competition and innovation.

In our analysis, we take a close look at the welfare implications of the presence of informal input suppliers. In this line, many studies have analyzed welfare in the presence of vertical differentiation, although with different modeling approaches than ours. For instance, Ronnen (1991) analyzes the welfare effects of imposing minimum quality standards. Amacher et al. (2005) compare the socially-optimal and equilibrium quality decisions with vertical differentiation to find that under fixed costs the social planner chooses just one quality level, as in Crampes and Hollander (1995), but two quality levels are socially optimal with variable costs. In a related contribution, Nguyen et al. (2014) considers licensing in a model of 
vertical differentiation and compares welfare under Bertrand and Cournot competition.

Finally, the nature of competition and the choice of the payment mechanism in the vertical transaction are also found to drive the results in models that feature a vertical structure ${ }^{1}$. For instance, Wang and $\mathrm{Li}$ (2020) consider an upstream monopolist using a two-part tariff and two horizontally differentiated firms to find that consumer surplus and social welfare decrease with the intensity of competition downstream and both are higher under Cournot than under Bertrand. We consider a similar vertical structure and the case of two-part tariffs, although we assume vertical differentiation and the existence of an alternative input source. In a similar framework to ours, Herweg (2012) uses a model that includes a three-stage game where firms decide on entry and then on (discrete) quality choices to show that quality differentiation exists if and only if two-part tariffs are feasible. In his model, two-part tariff competition decreases consumer surplus compared to linear pricing. In a similar way as in Herweg (2012), we conduct a welfare evaluation of the presence of informal input suppliers, for the cases of a linear price and two-part tariffs.

\section{The case of a downstream monopoly}

This section presents the model for the case of a single firm downstream. Section 4 will present an analogous analysis for the case of two downstream firms.

\subsection{Model setup}

We consider an industry where a formal upstream firm, denoted by $U$, sells an input of quality $s$ to a single downstream firm, denoted by $D_{1}$, which produces a final product that is purchased by consumers. We assume that the transformation capacity of $D_{1}$ is $\alpha \geq 1$. This means that if the quality level of the input purchased by $D_{1}$ is $s$, then the quality level of the product sold by $D_{1}$ is $\alpha s$. The downstream firm incurs in no costs other than the purchase of inputs from upstream firms.

We assume initially that the upstream firm chooses a wholesale price and that the downstream firm chooses output ${ }^{2}$. The formal upstream firm $U$ produces its input at zero marginal cost and has to choose the quality level $s \geq 1$ of its own input ${ }^{3}$. Doing so involves making a prior investment

$$
\phi(s)=\frac{m(s-1)^{2}}{2} .
$$

Thus, $m$ measures the productivity of the investment in quality upgrading, and if no investment is made, the upstream firm's quality level is one. Let $\pi_{U, j}^{M}(\cdot)$ denote the

\footnotetext{
1 The vertical transaction may determine market conduct downstream (Vetter 2017), or even be used for collusive purposes (Mendi 2009).

2 We discuss the case of price competition and two-part tariffs in Sect. 5.

3 Considering a positive marginal cost upstream does not alter the main conclusions from the model, while substantially complicating the analysis.
} 
upstream firm's gross profits, not considering the cost of investing in quality upgrade, in the case of a monopoly downstream. Subscript $j=\{I, N I\}$ denotes whether informal input suppliers are active. Similarly, $\pi_{1, j}^{M}(\cdot)$ denotes $D_{1}$ 's gross profits. As discussed below, the upstream firm's incentives to invest in quality upgrading are given by the comparison between $\frac{d \pi_{U j}^{M}(s)}{d s}$ and $\phi^{\prime}(s)$.

If active, informal input suppliers are a lower-quality alternative, producing an input with a quality level that is normalized to 1 . That is, the informal firms' quality level of inputs can not exceed that of the formal firm. Informal producers compete in prices and sell a non-differentiated product, which lowers its price to marginal cost, which is assumed to be zero.

On the demand side, we assume that consumers have heterogeneous tastes for quality as in Mussa and Rosen (1978), Gabszewicz and Thisse (1979) or Shaked and Sutton (1982, 1983). In particular we follow Mussa and Rosen (1978) in assuming that consumers differ in their willingness to pay for quality. Specifically, there is a unit mass of consumers with heterogeneous willingness to pay for quality, described by the parameter $\theta$, which follows a uniform distribution over the $[0,1]$ support. Every consumer consumes at most one unit of the goods being offered. If a consumer characterized by $\theta$ consumes a unit of a good with quality level $s$, and pays a price $p$, his net utility is given by $v(\theta)=s \theta-p$. Consumers choose whether to purchase depending on the net utility of each alternative. Therefore, if only one product with quality $s$ is being offered, demand is given by $p=s(1-q)$, and the market is not fully covered as long as the price is positive.

The specific timing of the game is as follows:

1. The upstream firm $U$ decides how much to invest in quality upgrading.

2. $U$ posts a wholesale price $w$ for its input. If active, the price posted by informal suppliers equals marginal cost, which we assume to be zero.

3. $D_{1}$ makes its procurement decision. This determines the quality levels of the product sold to final consumers.

4. $D_{1}$ chooses how much to produce. The output price and profits are realized.

\subsection{Analysis}

As it is usual in this type of games, we will analyze the game by means of backward induction: we will start with the final stage first, and then work our way backwards. Given $w$, in the final stage of the game, the downstream monopolist $D_{1}$ maximizes profits by choosing an output level $q_{1}^{M}(w)=\frac{\alpha s-w}{2 \alpha . s}$.

Regarding the upstream firm's choice of wholesale price, notice that its own gross profits as a function of $w$ are $\frac{\alpha s-w}{2 \alpha s} w$, which is a concave function of $w$, and whose maximum is at $w=\frac{\alpha s}{2}$. Now, in the absence of informal input suppliers, the downstream firm's outside option is zero. For this reason, the upstream firm chooses $\hat{w}_{N I}^{M}=\frac{\alpha s}{2}$, and the upstream firm's profits are $\hat{\pi}_{U, N I}^{M}=\frac{\alpha s-c}{8}$. This way, 


$$
\frac{d \pi_{U, N I}^{M}}{d s}=\frac{\partial q_{1, N I}^{*}}{\partial s} w_{N I}^{M}=\frac{\alpha}{8}
$$

In the presence of informal input suppliers, the monopolist must satisfy the downstream monopolist's acceptance constraint, and for this reason, it will be forced to choose a wholesale price that will typically be less than $\hat{w}_{N I}^{M}$. Since $D_{1}$ 's profits if using the informal producers' input equal $\frac{\alpha}{4}$, the acceptance constraint reads

$$
\frac{(\alpha s-w)^{2}}{4 \alpha s} \geq \frac{\alpha}{4}
$$

and it is easy to see that if (3) is binding, then, the chosen wholesale price equals $\tilde{w}_{I}^{M}=\alpha(s-\sqrt{s})$, and in this case, we find that

$$
\frac{d \pi_{U, I}^{M}}{d s}=\frac{\alpha s}{4 s \sqrt{s}}=\frac{\alpha}{4 \sqrt{s}}
$$

and this is indeed the solution as long if the following condition holds:

$$
\alpha(s-2 \sqrt{s}) \leq 0 .
$$

Therefore, $D_{1}$ 's constraint will be binding as long as $s \leq 4$. Then, if $s \leq 4$, the formal upstream firm's incentives to invest are greater with informal suppliers, whereas if $s>4$, incentives are identical.

\subsection{Welfare analysis}

Define the gross surplus as a function of $s_{1}$, the quality of the input used by downstream firm $D_{1}$ and $\alpha, D_{1}$ 's transformation capacity, as:

$$
S\left(s_{1}, \alpha\right)=\int_{0}^{q_{1}\left(s_{1}, \alpha\right)} \alpha s_{1}(1-t) d t=\alpha s_{1}\left(q_{1}\left(s_{1}, s_{2}, \alpha\right)-\frac{q_{1}\left(s_{1}, s_{2}, \alpha\right)^{2}}{2}\right)
$$

Notice that this function does not include the cost investment. Therefore, total welfare is defined as the difference between $S\left(s_{1}, \alpha\right)$ and $\phi(s)$. Also notice that $S$ allows us to consider the two relevant cases for the case of a monopoly downstream. If $D_{1}$ purchases from the formal upstream firm, then $s_{1}=s$, whereas if $D_{1}$ purchases from informal suppliers, then $s_{1}=1$. The comparison between (2) and (4) determines whether the incentives to invest in quality upgrading are greater in the presence or in the absence of informal input suppliers. This is summarized in the following lemma:

Lemma 3.1 If there is a single firm downstream then the upstream producer has at least a strong incentive to invest in quality upgrading in the presence of informal input suppliers than in the absence of informal input suppliers.

Proof Comparing the derivatives of the upstream firm's profit function with respect to $s$ in (2) and (4) we see that if $s \leq 4$, 


$$
\frac{\alpha}{4 \sqrt{s}}>\frac{\alpha}{8}
$$

and if $s>4$, then the presence of informal input suppliers does not alter the behavior of $U$ of $D_{1}$ and the incentives to invest are therefore the same.

Therefore, whenever (5) holds, $D_{1}$ 's acceptance constraint is binding and the incentives to invest are grater with informal input suppliers. This is because an increase in $s$, in addition to increasing the upstream firm's margin, relaxes the downstream firm's acceptance constraint. For this reason, incentives are at least as strong with informal input suppliers as in their absence. Note that this result does not depend on the value of $\alpha$. If $s>4$, incentives are the same with and without informal input suppliers, since their presence does not constrain $U$ 's choice of wholesale price.

Regarding welfare, the introduction of a higher-quality product guarantees an increase in total welfare. This is because the increase in upstream profits never exceed the increase in total surplus that the upgraded quality brings about.

Lemma 3.2 In the case of a downstream monopoly, a quality increase is a sufficient condition for welfare to increase with informal input suppliers.

Proof For any $\alpha, s, U$ never chooses too high a level of $s$, compared with what is socially optimal. First, if $U$ charges price $\alpha(s-\sqrt{s})$, which is the optimal price in the presence of informal input suppliers and $D_{1}$ 's acceptance constraint is binding, then the derivative of the gross surplus function is

$$
\frac{d S}{d s}=\frac{\alpha}{4 \sqrt{s}}
$$

which equals the derivative $\frac{d \pi_{U}}{d s}$. If $D_{1}$ 's acceptance constraint is non-binding, which is the case in the absence of informal input suppliers and also if there are informal input suppliers and $s$ is sufficiently high, then

$$
\frac{d S}{d s}=\frac{7 \alpha s}{32}>\frac{\alpha}{8}=\frac{d \pi_{U}}{d s}
$$

Then, it suffices to compare the incentives to invest with and without informal input suppliers. These incentives are never lower in the presence of informal input suppliers, therefore, welfare never decreases with informal input suppliers in the case of a monopoly downstream. This is summarized in the following proposition:

Proposition 3.3 In the case of a monopoly downstream, the presence of informal input suppliers is never welfare-decreasing.

Proof From Lemma 3.2 it suffices to compare $U$ 's incentives to invest with and without informal input suppliers. Since these incentives never decrease with informal input suppliers, as seen in Lemma 3.1 welfare never decreases with their presence. 
Therefore, in the case of a monopoly downstream, the presence of informal input suppliers is always welfare-increasing. This result is driven by the non-decreasing incentives to invest in quality upgrading in the presence of informal input suppliers.

\section{The case of a downstream duopoly}

In this section, we analyze the case of a duopoly downstream that compete in quantities with possibly vertically differentiated products. In the next subsection, we discuss how the model setup changes relative to the case of a downstream monopolist. We then analyze in turn the cases of a symmetric duopoly downstream $(\alpha=1)$ and an asymmetric duopoly downstream $(\alpha>1)$.

\subsection{Downstream duopoly versus downstream monopoly}

There are now two downstream firms $D_{1}$ and $D_{2}$ and we initially assume that the competition between $D_{1}$ and $D_{2}$ is in quantities. The game develops in the same way as in the case of a downstream monopoly. We assume that $D_{1}$ and $D_{2}$ 's choice in stage 3 of what input to purchase -whether the formal upstream firm or the informal producers' - is simultaneous. Regarding notation, let $\pi_{i, j}^{D}(\cdot)$ denote firm $i$ 's profits, where $i=\{U, 1,2\}$ denotes the upstream firm, $D_{1}$ and $D_{2}$, respectively. As in the case of a duopoly, subscript $j=\{I, N I\}$ denotes whether informal input suppliers are active.

We allow the two downstream firms to differ in their transformation capacities, which eventually translates into asymmetric qualities of the final products that they sell. Specifically, we assume that the transformation capacities of downstream firms $D_{1}$ and $D_{2}$ are $\alpha$ and 1 , respectively, where $\alpha \geq 1$. Of course, if $\alpha=1$ and both downstream firms purchase the same input, there is a symmetric duopoly downstream, and we will analyze separately the cases $\alpha=1$ and $\alpha>1$.

On the demand side, consumers consume at most one unit of one of the two products, and make their choices based on the net utility of each alternative. If two products, with qualities $s_{1}$ and $s_{2}$, with $s_{1}>s_{2}$ are offered, and quantities are $q_{1}$ and $q_{2}$ respectively, then prices $p_{1}$ and $p_{2}$ must be such that

$$
\alpha s_{1}\left(1-q_{1}\right)-p_{1}=s_{2}\left(1-q_{1}-q_{2}\right)-p_{2}
$$

leading to

$$
\begin{gathered}
p_{1}^{D}\left(q_{1}^{D}, q_{2}^{D}\right)=\alpha s_{1}\left(1-q_{1}^{D}\right)-s_{2} q_{2}^{D} \\
p_{2}^{D}\left(q_{2}^{D}, q_{1}^{D}\right)=s_{2}\left(1-\left(q_{1}^{D}+q_{2}^{D}\right)\right)
\end{gathered}
$$

The market is not fully covered as long as the price of the low-quality product is positive, and equilibrium prices are such that the last consumer that purchases the high-quality product is just indifferent between purchasing the high- or the lowquality product. The downstream firms' marginal costs, $c_{1}, c_{2}$, which may or may not be equal, are determined by the wholesale price posted by the formal input 
producer and possibly by informal input suppliers. Quantity competition downstream gives rise to a duopoly equilibrium with possibly asymmetric costs. In the case of a duopoly with transformation capacities $\alpha$ and 1 , costs $c_{1}$ and $c_{2}$ and input qualities $s_{1}$ and $s_{2}$, output levels at an equilibrium where both firms produce are:

$$
q_{1}^{D}\left(s_{1}, s_{2}, \alpha, c_{1}, c_{2}\right)=\frac{2 \alpha s_{1}-s_{2}-2 c_{1}+c_{2}}{4 \alpha s_{1}-s_{2}}, \quad q_{2}^{D}\left(s_{1}, s_{2}, \alpha, c_{1}, c_{2}\right)=\frac{s_{2}\left(\alpha s_{1}+c_{1}\right)-2 \alpha c_{2} s_{1}}{s_{2}\left(4 \alpha s_{1}-s_{2}\right)}
$$

where downstream firms' costs will be $w$ or zero depending on their input procurement decisions. In fact, in stage 3 downstream firms make their procurement decisions. If firm i's acceptance constraint is to be satisfied, then its profits if purchasing from the formal upstream firm must be at least as high as in the outside option. If informal input suppliers are not present, the downstream firms' outside option is zero. If they are present, non-acceptance profits are positive.

In stage 2, the formal upstream firm chooses the wholesale price to maximize its profits, given $s$. Then, provided that the upstream firm's marginal cost is zero, the optimal wholesale price is defined as

$$
w^{*}(s) \equiv \underset{w}{\arg \max }\left[\sum_{i} q_{i, j}^{*}(w, s)\right] w-\phi(s)
$$

where $q_{i, j}^{*}(w, s)$ is firm $i$ 's output given $s$ and $w$. The summation is across all firms that purchase from the formal supplier. Note that this output level could be zero. In the absence of informal input suppliers, the first-order condition of the problem, which defines the optimal wholesale price $w^{*}(s)$ reads:

$$
\left[\sum_{i} \frac{\partial q_{i, j}^{*}}{\partial w}\right] w+\sum_{i} q_{i, j}^{*}=0
$$

In the presence of informal input suppliers, this condition may not hold, being replaced by $D_{2}$ 's acceptance constraint being binding.

In the first stage, the upstream firm chooses the quality level $s$ to maximize its own profits, taking into consideration the downstream firm or firms' procurement decisions, as well as its own choice of wholesale price. That is,

$$
\max _{s \geq 1}\left[\sum_{i} q_{i, j}^{*}\left(w^{*}(s), s\right)\right] w^{*}(s)-\phi(s)
$$

where $\phi(\cdot)$ is given in (10). From the first-order condition of this problem, we see that

$$
\frac{d \pi_{U, j}}{d s}=\left[\sum_{i} \frac{\partial q_{i, j}^{*}}{\partial w} \cdot \frac{d w^{*}}{d s}+\sum_{i} \frac{\partial q_{i, j}^{*}}{\partial s}\right] w^{*}(s)+\left[\sum_{i} q_{i, j}^{*}\right] \frac{d w^{*}}{d s}-m(s-1)
$$

Finally, regarding welfare, define now the gross surplus as a function of $s_{1}$ and $s_{2}$, 
the quality of the input used by downstream firms $D_{1}$ and $D_{2}$, respectively, and $\alpha$, $D_{1}$ 's transformation capacity, as:

$$
\begin{aligned}
S\left(s_{1}, s_{2}, \alpha\right)= & \int_{0}^{q_{1}\left(s_{1}, s_{2}, \alpha\right)} \alpha s_{1}(1-t) d t+\int_{q_{1}\left(s_{1}, s_{2}, \alpha\right)}^{q_{1}\left(s_{1}, s_{2}, \alpha\right)+q_{2}\left(s_{1}, s_{2}, \alpha\right)} s_{2}(1-t) d t \\
= & \alpha s_{1}\left(q_{1}\left(s_{1}, s_{2}, \alpha\right)-\frac{q_{1}\left(s_{1}, s_{2}, \alpha\right)^{2}}{2}\right) \\
& +s_{2}\left(q_{2}\left(s_{1}, s_{2}, \alpha\right)-\frac{q_{1}\left(s_{1}, s_{2}, \alpha\right)^{2}}{2}-q_{1}\left(s_{1}, s_{2}, \alpha\right) q_{2}\left(s_{1}, s_{2}, \alpha\right)\right)
\end{aligned}
$$

Notice that, again, this function does not include the cost investment. Therefore, total welfare is defined as the difference between $S\left(s_{1}, s_{2}, \alpha\right)$ and $\phi(s)$. Also notice that $S$ encompasses the two relevant cases. If both $D_{1}$ and $D_{2}$ purchase the input from $U$, then $s_{1}=s_{2}=s$, and if only $D_{1}$ purchases the input from $U$ and $D_{2}$ purchases from the informal input suppliers, then $s_{1}=s$ and $s_{2}=1$.

It is worth mentioning that a social planner maximizes total surplus by allocating all production to the high-quality producer, $D_{1}$, and selling at marginal cost of production. This way, gross surplus equals $\frac{\alpha s}{2}$ and the socially optimal level of $s$ would be given by

$$
\frac{\alpha}{2}=m(s-1) \Rightarrow s=\frac{\alpha}{2 m}-1
$$

thus requiring $\alpha>2 m$ In the presence of a duopoly downstream, the welfare impact of the presence of informal input suppliers combine two opposite effects. On one hand, whenever informal input suppliers are present, both firms, $D_{1}$ and $D_{2}$ will be active, even if $\alpha>1$. This brings about an output expansion effect that is welfareincreasing. Furthermore, informal input suppliers raise the downstream firms' outside option, imposing a cap on the wholesale price posted by the firm, which is also welfare-increasing. However, there is a potentially negative effect of the presence of informal input suppliers, namely reduced investment in quality upgrading, giving rise to a lower value of $s$ if there are informal input suppliers. We analyze now under what circumstances this is the case. We show below that this case arises only when there is an asymmetric duopoly downstream, that is, for $\alpha>1$, specifically for $\alpha$ sufficiently high so that if informal suppliers are absent, $U$ decides to sell to both $D_{1}$ and $D_{2}$ but if informal suppliers are present, $U$ decides to sell to $D_{1}$ only. This reduces $U$ 's incentives to invest, which is welfare-decreasing. If this effect is strong enough, then the distortion in $U$ 's choice of $s$ may more than offset the outputexpansion effect associated with the presence of informal input suppliers. Since the cases $\alpha=1$ and $\alpha>1$ have different welfare implications, we analyze these two cases separately. 


\subsection{Symmetric duopoly, $\alpha=1$}

If $\alpha=1$, then both downstream firms are symmetric and hence have the same incentives. For this reason, in the absence of informal input suppliers, the upstream firm will always sell to both firms. This way, the upstream firm optimally chooses a wholesale price that equals $\hat{w}_{N I}=\frac{s}{2}$ and its incentives to invest in quality upgrading are determined by

$$
\frac{d \pi_{U, N I}}{d s}=\frac{1}{6}
$$

In contrast, if informal suppliers are active, the upstream firm has to decide whether to sell to both downstream firms or just to one of them, $D_{1}$. In the latter case, $U$ would like to impose a wholesale price that equals $\frac{s}{2}$, that is the same as in the absence of informal suppliers, but its behavior may be constrained by the presence of informal suppliers. Whether this is the case depends on whether $\tilde{w}_{I} \geq \frac{s}{2}$, where $\tilde{w}_{I}$ is the critical value of the wholesale price so that for any $w>\tilde{w}_{I}, D_{1}$ (and therefore $D_{2}$ as well) switch to the informal suppliers. Given the value of $\tilde{w}_{I}$ for $\alpha=1$, the chosen wholesale price will equal $\tilde{w}_{I}$ as long as

$$
\frac{s(4 s-1-3 \sqrt{s})}{4 s-1+3 \sqrt{s}} \leq \frac{s}{2}
$$

implying that for $s \in\left[0,\left(\frac{9}{8}+\frac{\sqrt{97}}{8}\right)^{2}\right] \approx[0,5.5512]$ the chosen price will be $\tilde{w}_{I}$.

\subsubsection{Welfare implications}

Now, comparing the incentives to engage in quality upgrading in the cases of absence and presence of informal input suppliers, it is easy to see that if $s>\left(\frac{9}{8}+\frac{\sqrt{97}}{8}\right)^{2}$, then the derivative of the upstream firm's profits with respect to $s$ will be the same as in the absence of informal input suppliers, since the chosen wholesale price is the same. This is because $s$ is high enough so that the downstream firms' acceptance constraints are non-binding, and thus condition (11) holds in both cases.

Lemma 4.1 If $\alpha=1$, the upstream firm has greater incentives to invest in the presence of informal input suppliers, provided that $s \leq\left(\frac{9}{8}+\frac{\sqrt{97}}{8}\right)^{2}$

If $s<\left(\frac{9}{8}+\frac{\sqrt{97}}{8}\right)^{2}$, then if informal input suppliers are present the downstream firm's acceptance constraints are binding, the wholesale price is given by (26) below, with $\alpha=1$, and condition (11) no longer holds. In this case, the incentives to invest in the presence of informal input suppliers are: 


$$
\frac{d \pi_{U, I}}{d s}=\left[\frac{-2 \tilde{w}_{I}}{3 s}+\frac{2\left(s-\tilde{w}_{I}\right)}{3 s}\right] \frac{d \tilde{w}_{I}}{d s}+\frac{2\left(\tilde{w}_{I}\right)^{2}}{3 s^{2}}
$$

where

$$
\frac{d \tilde{w}_{I}}{d s}=\frac{16 s^{2}-17 s+1+12 s^{\frac{3}{2}}+3 \sqrt{s}}{(4 s+3 \sqrt{s}-1)^{2}}
$$

yielding

$$
\frac{d \pi_{U, I}}{d s}=\frac{2 \sqrt{s}\left(3+9 \sqrt{s}-34 s+36 s^{\frac{3}{2}}+16 s^{2}\right)}{(4 s+3 \sqrt{s}-1)^{3}}
$$

and it turns out that for any $s \leq\left(\frac{9}{8}+\frac{\sqrt{97}}{8}\right)^{2} \approx 5.551$, the value of the derivative is larger in the case of informal input suppliers being present, that is, $\frac{d \pi_{U, I}}{d s} \geq \frac{d \pi_{U, N I}}{d s}$. Therefore, incentives to invest are greater in the presence of informal input suppliers.

Regarding welfare, it suffices to show that $U$ 's incentives to invest are lower than social incentives for any combination of $\alpha$ and $s$. This is reflected in the following proposition:

Proposition 4.2 In the case $\alpha=1$, the presence of informal input suppliers is never welfare-decreasing.

Proof With or without informal input suppliers, $U$ sells to both $D_{1}$ and $D_{2}$. If $s \leq\left(\frac{9}{8}+\frac{\sqrt{97}}{8}\right)^{2}, U$ chooses $\tilde{w}_{I}$. Comparing its own incentives to invest in $s$ with the social incentives, we see that if $\alpha=1$

$$
\begin{aligned}
\frac{d S}{d s} & =\frac{2 \sqrt{s}\left(3-7 \sqrt{s}-10 s+36 s^{\frac{3}{2}}+16 s^{2}\right.}{(4 s+3 \sqrt{s}-1)^{3}} \\
\frac{d \pi^{U}}{d s} & =\frac{2 \sqrt{s}\left(3+9 \sqrt{s}-34 s+36 s^{\frac{3}{2}}+16 s^{2}\right.}{(4 s+3 \sqrt{s}-1)^{3}}
\end{aligned}
$$

hence,

$$
\frac{d S}{d s}-\frac{d \pi^{U}}{d s}=\frac{16 \sqrt{s}(3 s-2 \sqrt{s})}{(4 s+3 \sqrt{s}-1)^{3}}>0
$$

Now, for $s>\left(\frac{9}{8}+\frac{\sqrt{97}}{8}\right)^{2}$, we have

$$
\frac{d S}{d s}=\frac{5}{18}>\frac{1}{6}=\frac{d \pi^{U}}{d s}
$$

Then, $U$ always has suboptimal incentives to invest, and a quality increase is a sufficient condition for welfare to increase. Then, we may conclude that for 
$s \leq\left(\frac{9}{8}+\frac{\sqrt{97}}{8}\right)^{2}$, the presence of informal input suppliers is welfare-increasing, because it increases $U$ 's incentives to invest in $s$, whereas in the case $s>\left(\frac{9}{8}+\frac{\sqrt{97}}{8}\right)^{2}$. Of course, whether $s$ falls on one side or the other of the threshold value depends on the value of $m$. In particular, for high values of $m$, the presence of informal suppliers will increase welfare, whereas for a sufficiently low $m$, the presence of informal input suppliers will be welfare-neutral.

Therefore, in the symmetric case, $\alpha=1$, where both downstream firms have the same incentives to accept or reject the upstream firm's offer, the upstream firm's incentives to invest in quality upgrading are not diminished by the presence of informal input suppliers. In this case, raising the quality level allows $U$ to further differentiate from informal input suppliers, relaxing $D_{1}$ and $D_{2}$ 's incentive constraints. This sort of "escape competition effect" is an added incentive for $U$ to invest in the presence of informal input suppliers.

\subsection{Asymmetric duopoly, $\alpha>1$}

Now, if $\alpha>1$, then we might find parameter values such that the set of firms that accept the upstream firm's offer is different with informal than without informal suppliers. This may have an effect on the upstream firm's incentives to invest. In particular, if both firms accept the upstream firm's offer in the absence of informal suppliers but only one does so in their presence, the result that has been obtained in this subsection may be reversed. First, in the absence of informal input suppliers, even though both downstream firms' outside options are zero, the acceptance constraints are different for $D_{1}$ and $D_{2}$. In particular, the downstream firms' gross profits if purchasing the formal firm's input at the posted wholesale price $w$, provided that both sell in equilibrium, are given by:

$$
\begin{aligned}
& \pi_{1}(w, w, \alpha s, s)=\frac{\alpha(s(2 \alpha-1)-w)^{2}}{s(4 \alpha-1)^{2}}, \\
& \pi_{2}(w, w, s, \alpha s)=\frac{(\alpha s-w(2 \alpha-1))^{2}}{s(4 \alpha-1)^{2}}
\end{aligned}
$$

It is easily verified that if the wholesale price $w$ is the same for both firms, then $D_{1}$ 's profits exceed those of $D_{2}$. Let $\tilde{w}_{N I}$ be the critical value of $w$ that makes $D_{2}$ 's acceptance constraint binding.

Regarding $U$ 's choice of the wholesale price, if $w \geq \alpha s$, then neither $D_{1}$ nor $D_{2}$ accepts the upstream firm's offer. Therefore, for values of $w<\alpha s$ depending on the value of $w$, we could have a duopoly of a monopoly downstream. In particular, if $w<\tilde{w}_{N I}=\frac{\alpha s}{2 \alpha-1}$ then both downstream firms are active, since this is the critical value of $w$ such that $D_{2}$ 's profits are zero if both downstream firms were to produce with cost $w$. However, for $\tilde{w}_{N I} \leq w \leq \alpha s$, only $D_{1}$ is active in the downstream market. Therefore, the solution of the upstream firm's problem might entail a duopoly or a monopoly downstream. The formal upstream firm's profits are: 


$$
\pi_{U}(w)= \begin{cases}\frac{w(s(3 \alpha-1)-2 \alpha w)}{s(4 \alpha-1)} & \text { if } w \leq \tilde{w}_{N I} \\ \frac{w(\alpha s-w)}{2 \alpha s} & \text { if } \tilde{w}_{N I} \leq w \leq \alpha s \\ 0 & \text { if } w>\alpha s\end{cases}
$$

The following lemma establishes that in the absence of informal input suppliers, $U$ 's decision whether to sell to $D_{1}$ and $D_{2}$ or to $D_{1}$ only depends on the value of $\alpha$.

Lemma 4.3 In the absence of informal input suppliers, if $\alpha<\frac{2+\sqrt{2}}{2}, U$ posts $\hat{w}_{N I}^{D}=$ $\frac{s(3 \alpha-1)}{4 \alpha}$ and both $D_{1}$ and $D_{2}$ purchase from $U$. If $\alpha \geq \frac{2+\sqrt{2}}{2}$, then $U$ posts $\hat{w}_{N I}^{M}=\frac{\alpha s}{2}$ and only $D_{1}$ purchases from $D_{1}$.

Proof Let $\hat{w}_{N I}^{M}$ be the upstream firm's optimal wholesale price if there was only one producer downstream $\left(D_{1}\right)$ and let $\hat{w}_{N I}^{D}$ be the upstream firm's optimal wholesale price if both firms, $D_{1}$ and $D_{2}$ produce positive output levels. Specifically, these values, together with the value of $w$ that makes $D_{2}$ 's acceptance constraint binding are:

$$
\hat{w}_{N I}^{D}=\frac{s(3 \alpha-1)}{4 \alpha}, \tilde{w}_{N I}=\frac{\alpha s}{2 \alpha-1}, \hat{w}_{N I}^{M}=\frac{\alpha s}{2} .
$$

It is always the case that $\hat{w}_{N I}^{M}>\hat{w}_{N I}^{D}$. Whether the upstream firm chooses a wholesale price that gives rise to a monopoly or a duopoly downstream depends on the specific realization of the parameter values. Compare the optimal duopoly and monopoly profits, that is, those if charging $\hat{w}_{N I}^{D}$ and $\hat{w}_{N I}^{M}$, respectively, we find that duopoly profits are greater if

$$
\frac{s(3 \alpha-1)^{2}}{8 \alpha(4 \alpha-1)}>\frac{\alpha s}{8} \Rightarrow \alpha \leq \frac{2+\sqrt{2}}{2}
$$

This means that for $\alpha \leq \frac{2+\sqrt{2}}{2}, U$ optimally chooses $\hat{w}_{N I}^{D}$. Notice that in order for $\hat{w}_{N I}^{D}<\tilde{w}-N I$, we need $\alpha<\frac{5+\sqrt{17}}{2}$. Since for any $\alpha<\frac{2+\sqrt{2}}{2} U$ chooses the optimal duopoly wholesale price and $\frac{2+\sqrt{2}}{2}<\frac{5+\sqrt{17}}{4}$, the relevant cutoff is $\frac{2+\sqrt{2}}{2}$.

Finally, regarding the upstream firm's decision to invest in quality upgrading, if the optimal price is $\hat{w}_{D}$, with $U$ selling to both $D_{1}$ and $D_{2}$,

$$
\frac{d \pi_{U, N I}}{d s}=\left[\frac{\partial q_{1, N I}^{*}}{\partial s}+\frac{\partial q_{2, N I}^{*}}{\partial s}\right] \hat{w}_{N I}^{D}=\frac{2 \alpha \hat{w}_{N I}^{D}}{(4 \alpha-1) s^{2}} \hat{w}_{N I}^{D}
$$

whereas if $U$ decides to sell to $D_{1}$ only, charging $\hat{w}_{N I}^{M}$,

$$
\frac{d \pi_{U, N I}}{d s}=\frac{\partial q_{1, N I}^{*}}{\partial s} \hat{w}_{N I}^{M}=\frac{\hat{w}_{N I}^{M}}{2 \alpha s^{2}} \hat{w}_{N I}^{M}
$$

Now, the presence of informal input suppliers guarantees the existence of a duopoly downstream, since $D_{2}$ can always buy the input from informal suppliers at zero 
price. Additionally, it increases the downstream firms' outside options. For this reason, the threshold values of $w$ such that $D_{2}$ and $D_{1}$ no longer purchase from the formal upstream firm are lower than in the absence of an alternative input source. Whether $U$ sells to both $D_{1}$ and $D_{2}$, to $D_{1}$ only or to neither firm depends on the realization of the parameters $\alpha$ and $s$. Since we are assuming that the formal upstream firm's cost is zero, $\alpha>1$ and $s>1$ guarantees that values of the wholesale price may be found such that at least $D_{1}$ purchases the formal firm's input. Indeed, we may find combinations of the parameter values such that both firms purchase from the formal supplier in the absence of informal input suppliers and only $D_{1}$ does in their presence. This certainly has an effect on the upstream firm's incentives to invest in quality upgrading, and ultimately on welfare.

The critical values of the wholesale price are determined as follows. First, the value of $\tilde{w}_{I}$ is the value that makes $D_{2}$ 's acceptance constraint binding, provided that $D_{1}$ purchases the input from the formal supplier at price $w$. That is,

$$
\frac{\left(\alpha s-\tilde{w}_{I}(2 \alpha-1)\right)^{2}}{s(4 \alpha-1)^{2}}=\frac{\left(\alpha s+\tilde{w}_{I}\right)^{2}}{(4 \alpha s-1)^{2}}
$$

therefore,

$$
\tilde{w}_{I}=\frac{\alpha s(4 \alpha s-1-\sqrt{s}(4 \alpha-1))}{\sqrt{s}(4 \alpha-1)+(2 \alpha-1)(4 \alpha s-1)} .
$$

On the other hand, the value of $\tilde{\tilde{w}}_{I}$ is defined as the wholesale price that makes $D_{1}$ 's acceptance constraint binding, provided that $D_{2}$ uses the input supplied by informal producers. This is:

$$
\frac{\alpha s\left(2 \alpha s-2 \tilde{\tilde{w}}_{I}-1\right)^{2}}{(4 \alpha s-1)^{2}}=\frac{\alpha(2 \alpha-1)^{2}}{(4 \alpha-1)^{2}}
$$

hence

$$
\tilde{\tilde{w}}_{I}=\frac{\sqrt{s}(2 \alpha s-1)(4 \alpha-1)-(2 \alpha-1)(4 \alpha s-1)}{2 \sqrt{s}(4 \alpha-1)}
$$

Now, if the upstream firm sells at wholesale price $w$ to both downstream firms, its profits are, as a function of $w$,

$$
\pi_{U, I}^{D}(w)=w \frac{3 \alpha s-s-2 \alpha w}{s(4 \alpha-1)}
$$

and the maximum of this function is at $\hat{w}_{I}^{D}=\frac{(3 \alpha-1) s}{4 \alpha}$. If it sells to $D_{1}$ only and $D_{2}$ uses the informal firms' input,

$$
\pi_{U, I}^{M}(w)=w \frac{(2 \alpha s-1-2 w)}{4 \alpha s-1}
$$

and the maximum of this function is at $\hat{w}_{N I}^{M}=\frac{2 \alpha s-1}{4}<\frac{\alpha s}{2}=\hat{w}_{N I}^{M}$. 
Let $\tilde{w}_{I}$ be defined as in (26) and $\tilde{\tilde{w}}_{I}$ be defined as in (28). Given $\alpha$ and $s, U$ 's optimal behavior depends on the wholesale price it is able to charge if selling to both $D_{1}$ and $D_{2}$ or to $D_{1}$ only, and on profits in each alternative. This means that we can divide the $\alpha, s$ space in several regions, as done in Figs. 1 and 2. First, Fig. 1 focuses on the case $\alpha<\frac{2+\sqrt{2}}{2}$, which implies that in the absence of informal input suppliers, $U$ sells to both $D_{1}$ and $D_{2}$, posting $\hat{w}_{N I}^{D}$. In the figure, the thin line that is almost vertical represents $\tilde{\tilde{w}}_{I}=\hat{w}_{I}^{M}$, and $U$ charges $\hat{w}_{I}^{M}$ to the right of this line. The thick line represents $\pi_{I}^{M} \geq \pi_{I}^{D}$ and $U$ optimally decides to sell to $D_{1}$ only above the line if informal input suppliers are present. Then, in region I, $U$ sells to both $D_{1}$ and $D_{2}$, charging $\tilde{w}_{I}$, in Region II, $U$ sells to $D_{1}$ only, charging $\tilde{\tilde{w}}_{I}$, and in Region III, $U$ sells to $D_{1}$ only, charging $\hat{w}_{I}^{M}$. Then, we see that, if $\alpha$ is close to one, that is, downstream firms are not very asymmetric, $U$ sells to both firms in the presence of informal input suppliers, but it optimally decides to switch to $D_{1}$ only as $\alpha$ increases. Crucially, the switch occurs for a lower value of $\alpha$ with than without informal input suppliers, as seen in Fig. 1.

In Region III, where $U$ sells to $D_{1}$ only, we may find combinations of $S, \alpha$ such that in the presence of informal input suppliers, $U$ sells to $D_{1}$ only and charges the monopoly price. If that is the case, $U$ 's incentives to engage in quality upgrading are given by

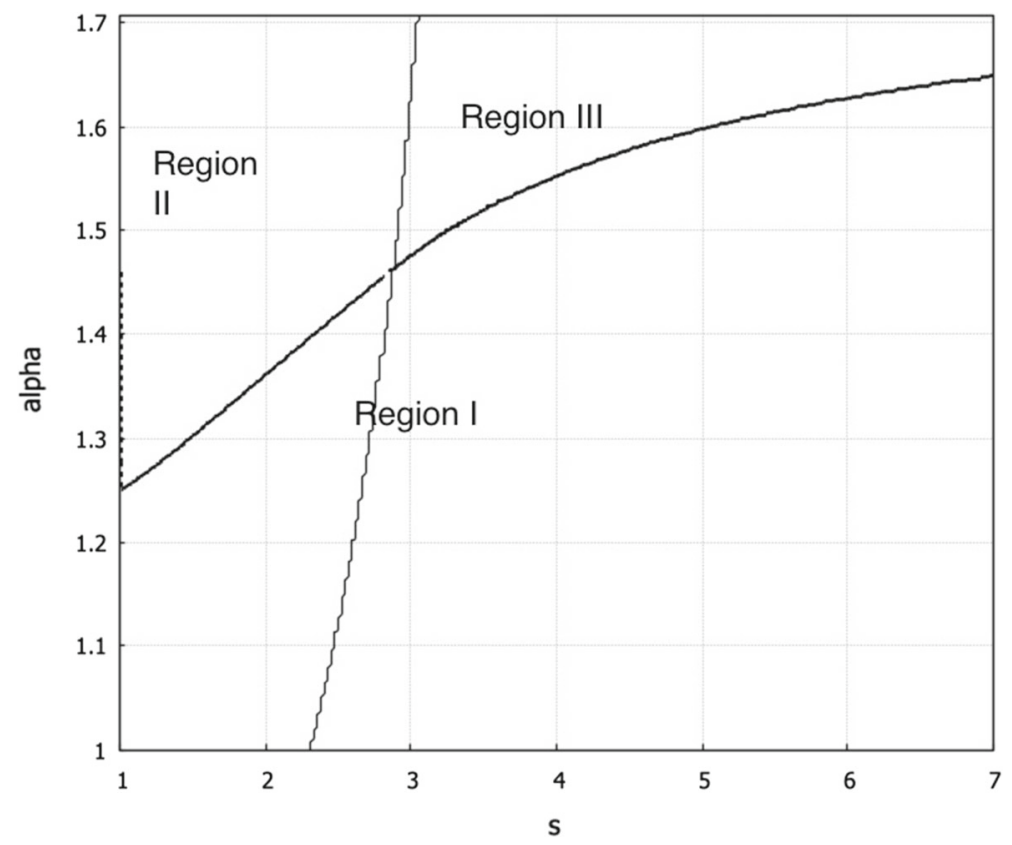

Fig. 1 Case $\alpha<\frac{2+\sqrt{2}}{2}$ 


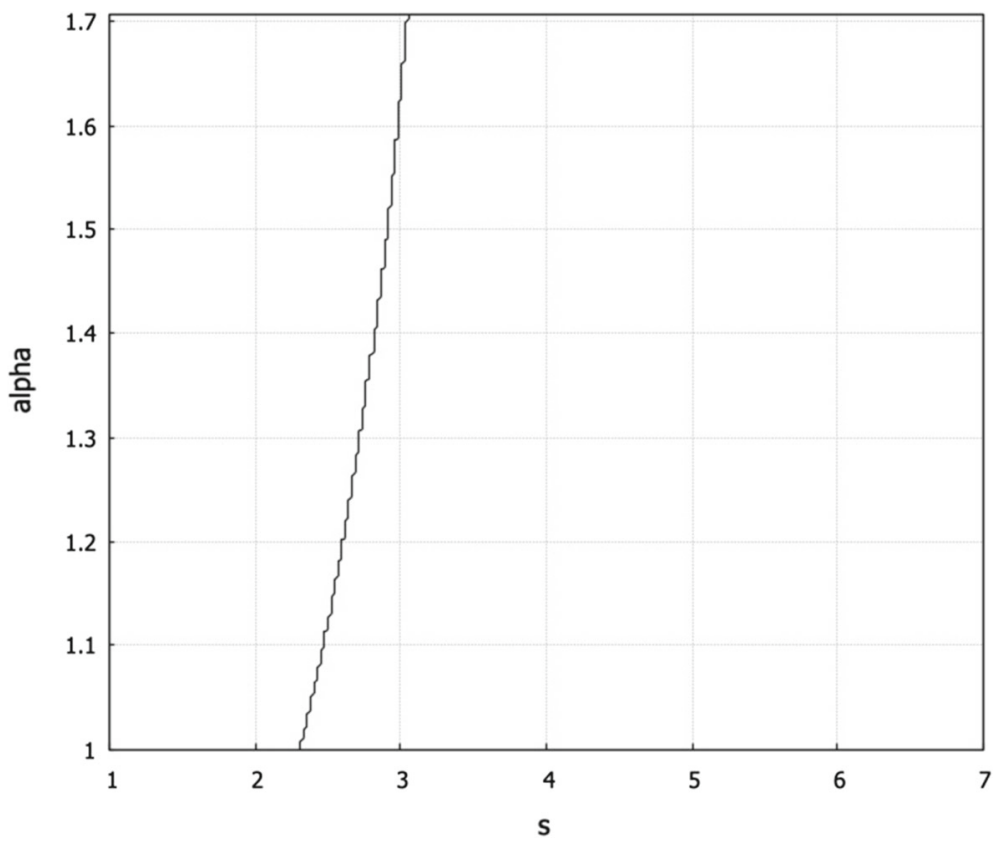

Fig. 2 Case $\alpha \geq \frac{2+\sqrt{2}}{2}$

$$
\frac{d \hat{\pi}_{U}^{M}}{d s}=\frac{\alpha^{2} s(2 \alpha s-1)}{(4 \alpha s-1)^{2}}
$$

Recall that in the absence of informal input suppliers, $U$ sells to both $D_{1}$ and $D_{2}$, charging $\hat{w}^{D}$. In this case, its incentives to invest in quality upgrading are:

$$
\frac{d \hat{\pi}_{U}^{D}}{d s}=\frac{(3 \alpha-1)^{2} s}{8 \alpha(4 \alpha-1)}
$$

and comparing the two, it turns out that incentives are greater in the absence of informal input suppliers, for values of $s, \alpha$ in the region of interest. This is important because it will increase the equilibrium value of $s$ in the absence of informal input suppliers, which is welfare-increasing. In order for this to be the case, the value of $m$ has to be such that the optimum with informal input suppliers is in that particular region.

Proposition 4.4 If $1<\alpha<\frac{2+\sqrt{2}}{2}$, there are combinations of values of $\alpha, m$ such that welfare decreases in the presence of informal input suppliers.

Proof Consider values of $\alpha$ in Region III of Fig. 1 such that $U$ sells to $D_{1}$ only with informal input suppliers and charges $\hat{w}_{I}^{M}$. Let $m$ be such that $\frac{d \hat{\pi}_{I}^{M}}{d s}=m$ at a value of $s$ in that region, call it $s(m)$. First, we may see that, for any $s, \alpha$ in that region, the difference between the gross surplus without informal input suppliers and with 
informal input suppliers, as a function of $s$ and $\alpha$ is given by the following expression:

$$
\begin{aligned}
\Delta S(s, \alpha)= & \frac{0.03125\left(1-7 \alpha-5 \alpha^{2}+111 \alpha^{3}-214 \alpha^{4}+192 \alpha^{5}\right) s}{\alpha^{2}(4 \alpha-1)^{2}}+ \\
& -\frac{0.03125\left(3-24 \alpha s+28 \alpha^{2} s^{2}-112 \alpha^{3} s^{3}\right.}{(4 \alpha s-1)^{2}}
\end{aligned}
$$

which is positive for all $s, \alpha$ in the region. Moreover, $U$ 's incentives to invest are greater without informal input suppliers, since

$$
\frac{d \pi_{N}^{U} I}{d s}-\frac{d \pi_{I}^{U}}{d s}=\frac{(3 \alpha-1)^{2}}{8 \alpha(4 \alpha-1)}-\frac{\alpha^{2} s(2 \alpha s-1)}{(4 \alpha s-1)^{2}},
$$

which is positive for every $s, \alpha$ in the region. Then, for the value of $m$ such that in the presence of informal input suppliers $U$ optimally chooses $s(m)$, in the absence of informal input suppliers, $U$ chooses a higher value of $s$. Welfare increases as long as the social incentives are greater than $U$ 's incentives to invest in quality upgrading. This is the case, since

$$
\frac{d S}{d s}-\frac{d \hat{\pi}_{N I}^{D}}{d s}=\frac{0.03125\left(1-7 \alpha-5 \alpha^{2}+111 \alpha^{3}-214 \alpha^{4}+192 \alpha^{5}\right)}{\alpha^{2}(4 \alpha-1)^{2}}-\frac{(3 \alpha-1)^{2}}{8 \alpha(4 \alpha-1)}
$$

and this is also positive for every $s, \alpha$ in the region.

The intuition for the result is relatively simple. If the asymmetry between the two downstream firms is such that the upstream firm is better off selling to just one firm in the presence of informal input suppliers but to both downstream firms in their absence, then an increase in the quality of the input increases relatively more the profits of the upstream firm in the case of selling to both downstream firms. This did not occur when $\alpha=1$, since their incentives to accept were the same and either both accepted or both rejected. However, the introduction of an asymmetry downstream, brought about by a value of $\alpha$ greater than one, allows for this possibility.

As an illustration, if $\alpha=1.6$, the value of $\frac{d \pi_{U}}{d s}$ with informal input suppliers at $s=3.5$ equals 0.1995 . This means that if $m=\frac{0.1995}{2.5} \approx 0.0798$, the optimal value of $S$ in the presence of informal input suppliers is 3.5. This yields a net surplus of 1.14373. If informal input suppliers are not present, then, for $m=0.0798$, then the optimal value of $s$ is $3.6179>3.5$, and net surplus is 1.3252 . Therefore, the presence of informal input suppliers is welfare-decreasing. Notice that this is the case even though total output increases with informal input suppliers. However, the reduced incentives to invest together with the fact that $D_{2}$ produces a lower-quality product (in this case, the substitution effect discussed in (Galera et al. 2017a, b) occurs in the absence of informal input suppliers) causes welfare to decrease with informal input suppliers.

As pointed out in the introduction, the main purpose of this paper is to show that welfare may decrease with informal input suppliers even though it always leads to 
increased competition, through a reduction in the formal upstream firm's incentives to invest. For this reason, we will not carry out a complete welfare analysis. In the rest of the regions, welfare typically increases with informal input suppliers. For instance, in Region I, it is easy to see that $U$ 's incentives to invest in the presence of informal input suppliers are greater than in their absence, and $U$ is forced to lower its wholesale price in their presence. In Region I, the effect on welfare is ambiguous, since in the presence of informal input suppliers, $U$ sells to $D_{1}$ only if informal input suppliers are present, but to both in their absence, but incentives are higher with informal input suppliers in most of Region II. Finally, for the case $\alpha \geq \frac{2+\sqrt{2}}{2}$, as seen in Fig. 2 if informal input suppliers are present, $U$ sells to $D_{1}$ only, charging $\tilde{\tilde{w}}_{I}$ to the right of the thin line, and $\hat{w}_{I}^{M}$ to the left of the line. While the incentives to invest are slightly higher without informal input suppliers if $U$ charges $\hat{w}_{I}^{M}$, since in the presence of informal input suppliers $D_{2}$ is always active, unlike in their absence, this positive effect on welfare more than offsets the reduced incentive to invest.

\section{Extensions: price competition and two-part tariffs}

We now proceed to discuss the robustness of our results to alternative assumptions, namely price competition downstream, and $U$ charging a two-part tariff instead of a wholesale price only.

\subsection{Price competition downstream}

First, if there is a single downstream firm with transformation capacity $\alpha$, the analysis is the same as in the case of quantity competition, precisely because there is a single firm downstream. In particular, in the absence of informal input suppliers, $U$ optimally chooses a wholesale price $w^{M}=\frac{\alpha s}{2}$, and the downstream firm produces an output level $q^{M}=\frac{1}{4}$. This way, $U$ 's incentives to invest in quality upgrading are given by $\frac{d \pi^{U}}{d s}=\frac{\alpha}{8}$. Meanwhile, in the presence of informal input suppliers, as argued above, the downstream firm's acceptance constraint may be binding for low values of $s$, specifically for $s \leq 4$. If that is the case, the optimal wholesale price is $\alpha s-\alpha \sqrt{s}$, whereas if $s>4, U$ may charge the wholesale price $w^{M}=\frac{\alpha s}{2}$ and the constraint is non-binding. For $s \leq 4, U$ 's incentives to invest are given by $\frac{d \pi^{U}}{d s}=\frac{\alpha}{4 \sqrt{s}}>\frac{\alpha}{8}$.

With two firms downstream, if $D_{1}$ and $D_{2}$ charge prices $p_{1}$ and $p_{2}$, respectively, and if both firms sell positive output levels, quantities are given by

$$
q_{1}\left(p_{1}, p_{2}\right)=\frac{\alpha s_{1}-s_{2}-p_{1}+p_{2}}{\alpha s_{1}-s_{2}} \quad q_{2}\left(p_{1}, p_{2}\right)=\frac{\alpha s_{1} p_{2}-s_{2} p_{1}}{s_{2}\left(\alpha s_{1}-s_{2}\right)}
$$

If $\alpha=1$, the model boils down to the standard Bertrand model, therefore, $p_{1}=p_{2}=w$. In this case, $U$ 's optimal behavior in the absence of informal input suppliers is to set $w=\frac{s}{2}$, yielding a total output $\frac{1}{2}$ and $U$ 's profits are $\frac{s}{4}$. However, in the presence of informal input suppliers, notice that for any $w>0$, a unilateral 
deviation from the equilibrium where both $D_{1}$ and $D_{2}$ accept $U$ 's wholesale price brings about positive profits, therefore, $U$ can not implement any $w>0$ that is accepted by both downstream firms. Therefore, the equilibrium will involve just one of the two firms accepting, say $D_{1}$. Then, $D_{1}$ 's reservation profits are those made if deviating and purchasing from informal input suppliers, given that $D_{2}$ also purchase from informal input suppliers, that is zero because of price competition and lack of vertical differentiation. In this case, $U$ 's optimal wholesale price is $w=\frac{s(s-1)}{2 s-1}$.

If $\alpha>1$, in the absence of informal input suppliers if $w<\frac{s}{2}$ and both downstream firms produce in the price equilibrium purchasing $U$ 's input at price $w$, where prices are

$$
p_{1}^{*}=\frac{\alpha(2 s(\alpha-1)+3 w)}{4 \alpha-1} \quad p_{2}^{*}=\frac{s(\alpha-1)+w(2 \alpha+1)}{4 \alpha-1}
$$

If $\frac{s}{2} \leq w<\frac{\alpha s}{2 \alpha-1}, D_{1}$ chooses $p=\alpha w$ and $D_{2}$ chooses $p_{2}=w$, but makes zero sales. Finally, if $w \geq \frac{\alpha s}{2 \alpha-1}$, then $D_{1}$ chooses the monopoly price, $p_{1}^{M}=\frac{\alpha s+w}{2}$, and $D_{2}$ chooses $p_{2}=w$ but makes no sales either. Like in the case of price competition, the market is not fully covered.

Regarding $U$ 's optimal behavior in the absence of informal input suppliers, for $\alpha<2, U$ sets $w=\frac{s}{2}$ and $U$ 's profits are $\frac{s}{4}$. For $\alpha \geq 2, U$ 's optimal wholesale price equals $w=\frac{\alpha s}{2}$, inducing $D_{1}$ to behave as an unconstrained monopolist, and making $U$ 's profits be $\frac{\alpha s}{8}$. This means that if $\alpha<2, \frac{d \pi_{N I}^{U}}{d s}=\frac{1}{4}$, whereas if $\alpha \geq 2, \frac{d \pi_{N I}^{U}}{d s}=\frac{\alpha}{8}$.

The presence of informal input suppliers raises the downstream firms' outside options, and $U$ will choose to sell to $D_{1}$ only. The alternative would be to lower the wholesale price to satisfy $D_{2}$ 's acceptance constraint, and thus induce $D_{2}$ to purchase, but this is not profitable for $U$. Then, $D_{1}$ purchases from $U$ and operates with marginal cost $w$, whereas $D_{2}$ purchases from the informal input suppliers, thus using a input with quality 1 , at zero cost. The fact that $D_{2}$ operates with zero marginal cost, even though its product will be of lower quality, guarantees that $D_{2}$ 's market share will be positive. In this situation, $D_{1}$ and $D_{2}$ 's reaction functions are:

$$
p_{1}\left(p_{2}\right)=\max \left\{w, \frac{\alpha s-1+p_{2}}{2}\right\} \quad p_{2}\left(p_{1}\right)=\max \left\{0, \frac{p_{1}}{2 \alpha s}\right\}
$$

and, in equilibrium,

$$
p_{1}^{*}=\frac{2 \alpha s(\alpha s+w-1)}{4 \alpha s-1} \quad p_{2}^{*}=\frac{\alpha s+w-1}{4 \alpha s-1}
$$

yielding output levels

$$
q_{1}^{*}=\frac{2 \alpha s(\alpha s-1)-w(2 \alpha s-1)}{(\alpha s-1)(4 \alpha s-1)} \quad q_{2}^{*}=\frac{\alpha s(\alpha s+w-1)}{(\alpha s-1)(4 \alpha s-1)}
$$

With informal input suppliers, $D_{1}$ 's outside option is given by rejection profits, provided that $D_{2}$ purchases from informal input suppliers too. In this case, $D_{1}$ 's rejection profits are $\frac{4(\alpha-1) \alpha^{2}}{(4 \alpha-1)^{2}}>0$. On the other hand, $D_{1}$ 's acceptance profits if $U$ 
posts $w$, provided that $D_{2}$ uses the informal input suppliers' input, equal $\frac{(2 \alpha s(\alpha s-1)-w(2 \alpha s-1))^{2}}{(\alpha s-1)(4 \alpha s-1)^{2}}$.

These reservation profits may constrain $U$ 's choice of wholesale price. In particular, the wholesale price must satisfy $D_{1}$ 's acceptance constraint, that is:

$$
\frac{(2 \alpha s(\alpha s-1)-w(2 \alpha s-1))^{2}}{(\alpha s-1)(4 \alpha s-1)^{2}} \geq \frac{4(\alpha-1) \alpha^{2}}{(4 \alpha-1)^{2}},
$$

which effectively imposes an upper bound on the wholesale price that $U$ may set. Specifically,

$$
w \leq \bar{w}=\frac{2 \alpha s(4 \alpha-1)(\alpha s-1)-2 \alpha(4 \alpha-1) \sqrt{1-\alpha+\left(\alpha^{2}-\alpha\right) s}}{(2 \alpha s-1)(4 \alpha-1)}
$$

Now, if $D_{1}$ 's acceptance constraint is non-binding, given that $U$ ends up selling to $D_{1}$ only, from $U$ 's maximization problem, we find that the optimal wholesale price is $w^{*}=\frac{\alpha s(\alpha s-1)}{2 \alpha s-1}$. Then $U$ 's optimal profits are:

$$
\pi_{I}^{U}=\frac{\alpha^{2} s^{2}(\alpha s-1)}{(2 \alpha s-1)(4 \alpha s-1)}
$$

The comparison $w^{*}$ and $\bar{w}$ yields a not very tractable expression. However, the equality $w^{*}=\bar{w}$ defines an implicit function $\alpha(s)$ in the $s, \alpha$ space, which is represented as the thin line in Fig. 3. This line defines two regions: in Region I, $U$ may

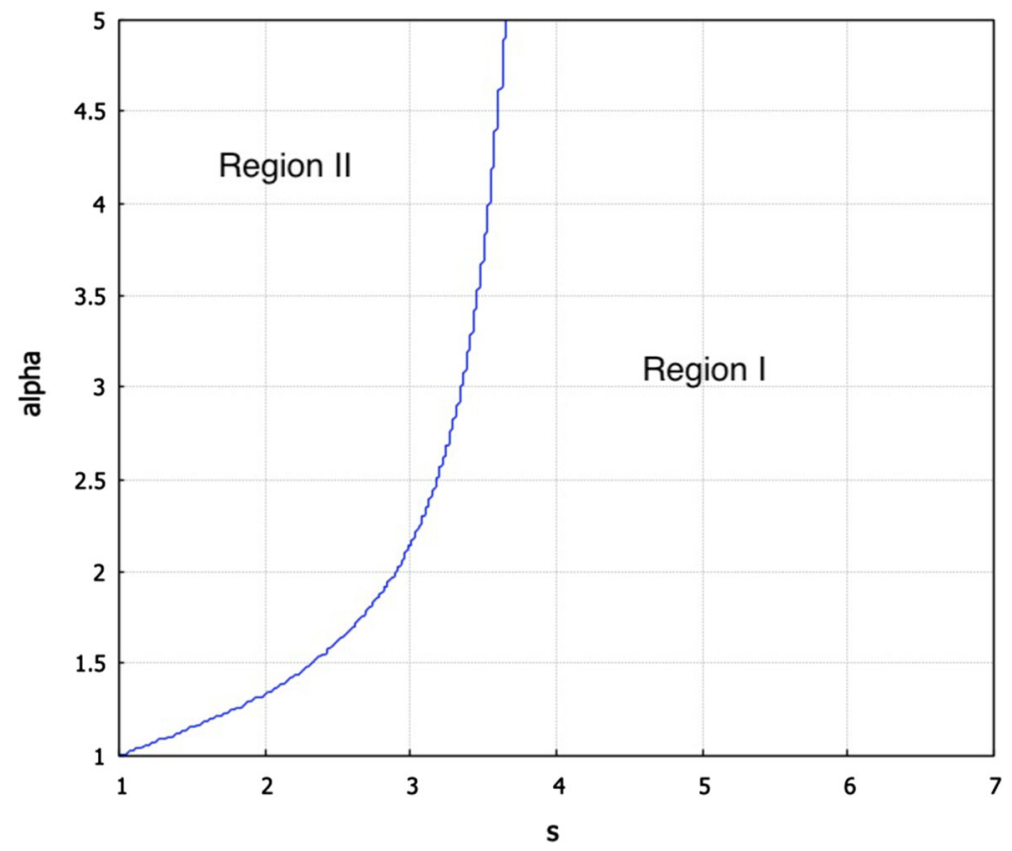

Fig. 3 Price competition 
implement $w^{*}$, whereas in Region II, $U$ is constrained to implementing $\bar{w}$. For instance, notice that for the case $\alpha=1, w^{*}=\frac{s(s-1)}{2 s-1}<\frac{2 s(s-1)}{2 s-1}=\bar{w}$, meaning that $U$ may implement $w^{*}$ for any value of $s$, which is illustrated by the fact that the whole horizontal axis belongs to Region I.

Regarding the incentives to invest, if $D_{1}$ 's acceptance constraint is non-binding, the expression for $\frac{\partial \pi_{I}^{U}}{\partial s}$ is:

$$
\frac{\partial \pi_{I}^{U}}{\partial s}=\frac{\alpha^{2} s\left(8 \alpha^{3} s-12 \alpha^{2} s^{2}+9 \alpha s-2\right)}{(2 \alpha s-1)^{2}(4 \alpha s-1)^{2}}
$$

Now, recall that for $\alpha<2$, in the absence of informal input suppliers, $U$ optimally chooses $w=\frac{s}{2}$, yielding profits $\frac{s}{4}$. If $\alpha \geq 2, U$ sets $s=\frac{\alpha s}{2}$, yielding profits $\frac{\alpha}{8}$. Then, the expression for $\frac{\partial \pi_{N I}^{U}}{\partial s}$ is $\frac{1}{4}$ for $\alpha<2$ and $\frac{\alpha}{8}$ for $\alpha \geq 2$.

Comparing $U$ 's incentives to invest, with and without informal input suppliers, we see that for $\alpha>2$, the difference

$$
\frac{\partial \pi_{I}^{U}}{\partial s}-\frac{\partial \pi_{N I}^{U}}{\partial s}=\frac{\alpha^{2} s\left(8 \alpha^{3} s-12 \alpha^{2} s^{2}+9 \alpha s-2\right)}{(2 \alpha s-1)^{2}(4 \alpha s-1)^{2}}-\frac{\alpha}{8}=\frac{\alpha\left(20 \alpha^{2} s^{2}-4 \alpha s-1\right)}{8(2 \alpha s-1)^{2}(4 \alpha s-1)^{2}}
$$

is positive for any $\alpha \geq 2$. For this reason, incentives to invest in quality upgrading are greater with informal input suppliers in Region I and $\alpha \geq 2$. This is also the case when $s, \alpha$ are in Region II and $\alpha \geq 2$. Therefore, the level of investment is greater with informal input suppliers and, since $U$ 's incentives to invest fall short of the social incentives, welfare increases with informal input suppliers for $\alpha \geq 2$.

We need to verify whether we can find parameter values such that welfare decreases with informal input suppliers for the case $\alpha<2$. In Region I, the difference in $U$ 's incentives is now

$$
\frac{\partial \pi_{I}^{U}}{\partial s}-\frac{\partial \pi_{N I}^{U}}{\partial s}=\frac{\alpha^{2} s\left(8 \alpha^{3} s^{3}-12 \alpha^{2} s^{2}+9 \alpha s-2\right)}{(2 \alpha s-1)^{2}(4 \alpha s-1)^{2}}-\frac{1}{4}
$$

This is a not very tractable expression. However, this is negative for most values of $\alpha<2$ and any values of $s$, which will allow us to find combinations of parameter values such that welfare decreases with informal input suppliers. Unlike in the case of quantity competition, in the case of price competition, the welfare decrease is brought about by a decrease in $U$ 's choice of $s$ with informal input suppliers. This is because without informal input suppliers only $D_{1}$ operates, whereas with informal input suppliers, both $D_{1}$ and $D_{2}$ are active, which is welfare-enhancing. Indeed, if $\alpha=1$,incentives to invest are greater without informal input suppliers, unlike in the case of quantity competition, as shown in the following proposition.

Proposition 5.1 If $\alpha=1$, there are values of $m$ such that welfare decreases with informal input suppliers.

Proof In the presence of informal input suppliers, if $\alpha=1, U$ optimally chooses $w=\frac{s(s-1)}{2 s-1}$, yielding profits $\pi_{U}=\frac{s^{2}(s-1)}{(2 s-1)(4 s-1)}$. This implies that $\frac{d \pi_{I}^{U}}{d s}=\frac{s\left(8 s^{3}-12 s^{2}+9 s-2\right)}{(2 s-1)^{2}(4 s-1)^{2}}$, 
which is a continuous, decreasing function of $s$, with $\lim _{s \rightarrow \infty} \frac{d \pi_{I}^{U}}{d s}=\frac{1}{8}$. For sufficiently high $s, \frac{d \pi_{I}^{U}}{d s}<\frac{1}{4}$, which is the derivative of $U$ 's profits with respect to $s$ in the absence of informal input suppliers. Then, the lower the value of $m$, the greater the distortion in the optimal value of $s$. This may eventually more than offset the positive impact on welfare of increased competition by informal input suppliers.

In particular, for every $m$ define $s_{I}$ and $s_{N I}$ as $m\left(s_{I}-1\right)=\frac{d \pi_{I}^{U}}{d s}$ and $m\left(s_{N I}-1\right)=\frac{d \pi_{N I}^{U}}{d s}$, respectively. These values exist because both $\frac{d \pi_{I}^{U}}{d s}$ and $\frac{d \pi_{N I}^{U}}{d s}$ are continuous, non-increasing functions of $s$ and $\phi^{\prime}(s)$ increases with $s$. Unfortunately, the expression for $\frac{d \pi_{I}^{U}}{d s}$ involves high-order polynomials in $s$ and the solutions of the equations that define $s_{I}$ and $s_{N I}$ can not be dealt with analytically. By resorting to numerical analysis, one can easily find a value of $m$ such that welfare decreases with informal input suppliers. For instance, this is the case for $m=0.01: s_{I}$ and $s_{N I}$ are such that welfare decreases with informal input suppliers. Since the difference between $s_{I}$ and $s_{N I}$ increases as $m$ decreases, the set of values of $m$, given $\alpha=1$, such that welfare decreases with informal input suppliers is non-empty.

Given that we have established that it is possible to find values of $m$ such that welfare decreases with informal input suppliers for $\alpha=1$, we can also find them for $\alpha>1$. This result is presented in the following proposition.

Proposition 5.2 If $1<\alpha<2$, there are parameter values such that welfare decreases with the presence of informal input suppliers.

Proof We showed in Proposition 5.1 that, for $\alpha=1$, the set of values of $m$ such that welfare decreases with informal input suppliers is non-empty. Take a value of $m$ such that welfare decreases with informal input suppliers if $\alpha=1$. Using continuity of $\frac{d \pi_{I}^{U}}{d s}$, if we raise the value of $\alpha$, the value of this derivative increases, but there are values of $\alpha$ close to one such that welfare is still greater without informal input suppliers. Therefore, for $\alpha>1$, we can find values of $m$ such that welfare decrases with informal input suppliers.

Summarizing, unlike in the case of quantity competition, in the case of price competition, when there is symmetry, that is, $\alpha=1$, we may find values of $m$ such that welfare decreases with informal input suppliers. This is because both in the absence and in the presence of informal input suppliers, $U$ sells to one of the two downstream firms only, and this reduces its own incentives to invest in quality upgrading. If the cost of investing is low enough, this may be more than offset the positive effect on welfare of the presence of a downstream competitor that purchases from informal input suppliers, making welfare to decrease with informal input suppliers, relative to the case of no informal input suppliers. As $\alpha$ increases, $U$ 's incentives to invest in the case of informal input suppliers being present grow, which reduces the distortion in $U$ 's investment, relative to the case when informal suppliers are absent. Eventually, for high enough $\alpha$, incentives to invest are greater with informal input suppliers and welfare always increases with their presence. 


\subsection{Two-part tariffs}

We now proceed to consider another exception of the basic analysis, namely the possibility of $U$ using two-part tariffs, assuming quantity competition, as in the benchmark model. If $U$ may introduce two-part tariffs, this possibility provides the formal upstream firm with an additional instrument to extract surplus. This way, in contrast to the case of a wholesale price only, the formal upstream firm will typically choose to sell to only one of the two downstream firms. As we will immediately see, this has an important effect on the upstream firm's incentives to invest in quality.

If there is a single firm downstream, in the absence of informal input suppliers, the formal upstream firm will be able to collect, by means of the fixed fee $F$, the full monopoly profits, since the downstream firm's outside option is zero. The wholesale price will be zero, so as to maximize the downstream firm's profits. The presence of informal input suppliers will impose an upper bound on the value of $F$, given by the level of rejection profits. Since these rejection profits equal $\frac{\alpha}{4}$ and do not depend on $s$, then the incentives to invest are not altered by the presence of informal input suppliers.

In the case of two downstream firms, in the absence of informal input suppliers and if $\alpha=1$, a Nash equilibrium is the upstream firm choosing $w=0$, a fixed fee equal to monopoly profits, and only one of the firms accepts, whether $D_{1}$ or $D_{2}$. In the case of an asymmetric duopoly $(\alpha>1)$ and in the absence of informal input suppliers, the fixed fee will be equal to the monopoly profits of firm $D_{1}$. Now, the presence of informal input suppliers on one hand guarantees the presence of a duopoly downstream and on the other, raises the downstream firm's outside option. In particular, $D_{1}$ does not accept a contract where it makes less than what it would make if resorting to informal input suppliers and facing competition against a rival that also purchases from informal input suppliers. This profit level, which equals $\frac{\alpha^{2}}{(4 \alpha-1)^{2}}$, does not depend on $s$. This implies that the upstream firm's incentives to invest in quality upgrading are given by the derivative of downstream asymmetric duopoly profits, those of $D_{1}$ (less a constant term). These incentives are stronger than in the case when $U$ collects monopoly profits, therefore if there is an asymmetric duopoly downstream, welfare never decreases with informal input suppliers. This is summarized in the following proposition:

Proposition 5.3 If the formal upstream firm uses a two-part tariff $(F, w)$, the presence of informal input suppliers is never welfare-decreasing.

Proof First with a monopoly downstream, the presence of informal input suppliers raises the downstream firm's reservation profits by $\frac{\alpha}{4}$, which does not depend on $s$.

With a symmetric duopoly downstream $(\alpha=1)$, the formal upstream firm sells to just one of the two firms, at $w=0$, and the presence of informal input suppliers raises the downstream firm's reservation profits by $\frac{1}{3}$. Then, with informal input suppliers, the upstream firm's profits are duopoly profits, whereas without informal input suppliers, these are monopoly profits. The difference in the first derivatives with respect to $s$ is: 


$$
\frac{\alpha(2 \alpha s-1)\left(8 \alpha^{2} s^{2}-2 \alpha s+1\right)}{(4 \alpha s-1)^{3}}-\frac{\alpha}{4}=\frac{\alpha(4 \alpha s-3}{4(4 \alpha s-1)^{3}},
$$

which is positive for every $s \geq 1$ and $\alpha \geq 1$.

\section{Conclusions}

While the effect of the operations of informal firms has attracted the attention of economists, most research efforts have been devoted to the study of informality downstream in the value chain. This paper contributes to filling a void in the literature and analyze the impact of informality upstream, and in particular on formal upstream firms' incentives to invest. We propose a theoretical model to analyze the impact on an upstream firm's incentives to invest in quality upgrading of the presence of informal input suppliers. As in Mendi (2015), we model informal firms as a competitive fringe that offers a lower-quality input at marginal cost, and this competitive fringe effectively constitutes an alternative input source for downstream firms, affecting the formal upstream firm's ability to charge a high wholesale price.

We show that the upstream firm's incentives to invest in quality upgrading depend crucially on the downstream market structure and on the degree of asymmetry between downstream firms. In particular, assuming quantity competition, if there is a monopoly downstream or a symmetric duopoly downstream, the presence of informal input suppliers never decreases the incentives to invest on the side of the upstream firm, and welfare never increases with the presence of informal suppliers, since the formal upstream firm's incentives to invest are smaller than social incentives.

However, when there is an asymmetric duopoly downstream, then there are parameter values such that the upstream firm's incentives to invest may be greater in the absence of informal input suppliers. This is the case when the asymmetry is high enough so that in the absence of informal input suppliers the upstream firm manages to sell to both firms, whereas it only sells to the most efficient firm in the presence of informal input suppliers. In this case, on one hand the presence of informal input suppliers reduces the incentives to invest, thus lowering the quality level of the output of the downstream firms. On the other hand, in the presence of informal input suppliers, the downstream firm with lower transformation capacity ends up producing a lower-quality product. These two effects are welfare-decreasing, and may more than offset the positive effect on welfare brought about by the increased competition introduced by the presence of informal input suppliers.

We consider two extensions of the basic model. First, we deal with price competition downstream. We find that there are also parameter values such that welfare decreases with informal input suppliers due to reduced incentives to invest on the formal upstream firm's side. This reduction in welfare may be obtained, for a low enough value of the cost of investment parameter, even with a symmetric duopoly downstream, a result that did not arise under quantity competition. As the degree of asymmetry downstream increases, the set of values of the cost of 
investment parameter such that welfare decreases with informal input suppliers is reduced, to completely disappear if the asymmetry is big enough. In the case of twopart tariffs, since the formal upstream firm always chooses to sell to one of the two downstream firms, the incentives to invest in quality upgrading are at least as strong with informal input suppliers, and the negative impact on welfare that arises from reduced investment is not present, therefore, welfare does not decrease with informal input suppliers. Finally, a number of interesting extensions may be introduced, but which we believe fall outside the scope of this paper, such as the use of discriminatory pricing by the formal upstream firm, or variations in the allocation of bargaining power between the upstream and the downstream firms. These extensions are left for future research.

In view of the different welfare implications depending on the parameter values and on the nature of competition, we believe our model is of relevance for the design of policies dealing with informality in developing countries, since it suggests that a one-size-fits all approach may not be adequate, but rather, a careful evaluation of the specific industry being considered is called for.

Acknowledgements We thank conference participants at the 7th International Research Meeting in Business and Management and XXXI Jornadas de Economía Industrial, as well as seminar participants at Universidad de Navarra for their helpful comments. Financial support from Fundación Ramón Areces and from Ministerio de Ciencia, Innovación y Universidades (PGC2018-098131-B-I00) is gratefully acknowledged. All errors are our own.

Funding Open Access funding provided thanks to the CRUE-CSIC agreement with Springer Nature.

Open Access This article is licensed under a Creative Commons Attribution 4.0 International License, which permits use, sharing, adaptation, distribution and reproduction in any medium or format, as long as you give appropriate credit to the original author(s) and the source, provide a link to the Creative Commons licence, and indicate if changes were made. The images or other third party material in this article are included in the article's Creative Commons licence, unless indicated otherwise in a credit line to the material. If material is not included in the article's Creative Commons licence and your intended use is not permitted by statutory regulation or exceeds the permitted use, you will need to obtain permission directly from the copyright holder. To view a copy of this licence, visit http:// creativecommons.org/licenses/by/4.0/.

\section{References}

Aghion P, Bloom N, Blundell R, Griffith R, Howitt P (2005) Competition and innovation: an inverted-U relationship. Quart J Econ 120(2):701-728

Amacher GS, Koskela E, Ollikainen M (2005) Quality competition and social welfare in markets with partial coverage: new results. Bull Econ Res 57(4):391-405

Arrow K (1962) The rate and direction of inventive activity: economic and social factors, chapter economic welfare and the allocation of resources for invention. National Bureau of Economic Research, Inc, pp. 609-626

Avenel E, Caprice S (2006) Upstream market power and product line differentiation in retailing. Int J Ind Organ 24(2):319-334

Banerji A, Jain S (2007) Quality dualism. J Dev Econ 84:234-250

Brécard D (2010) On production costs in vertical differentiation models. Econ Lett 109(3):183-186

Crampes C, Hollander A (1995) Duopoly and quality standards. Eur Econ Rev 39(1):71-82

De Soto H (1989) The other path: the invisible revolution in the third world. Harper and Row, New York 
De Soto H (2000) The mistery of capital: why capitalism triumphs in the west and fails everywhere else. Basic Books, New York

Farrell D (2004) The hidden dangers of the informal economy. McKinsey Quart 3:27-37

Gabszewicz J, Thisse J (1979) Price-competition, quality and income disparities. J Econ Theory 20(3):340-359

Galera F, Mendi P, Molero JC (2017) Quality differences, third-degree price discrimination, and welfare. Econ Inq 55(1):339-351

Galera F, Mendi P, Molero JC (2017) Seasonality, price discrimination, and welfare. J Econ 120(3):269-277

Herguera I, Kujal P, Petrakis E (2002) Tariffs, quality reversals and exit in vertically differentiated industries. J Int Econ 58:467-492

Herweg F (2012) Relaxing competition through quality differentiation and price discrimination. J Econ 106(1):1-26

Jinji N (2003) Strategic policy for producto R\&D with symmetric costs. Canad J Econ 36(4):993-1006

La Porta R, Shleifer A (2014) Informality and development. J Econ Perspect 28(3):109-126

Liu X (2016) Vertical integration and innovation. Int J Ind Organ 47(Supplement C):88-120

Loayza N (2016) Informality in the process of development and growth. Policy research working paper 7858, The World Bank

McGahan AM (2012) Challenges of the informal economy to the field of management. Acad Manag Perspect 26(3):12-21

Mendi P (2009) Backward integration and collusion in a duopoly model with asymmetric costs. J Econ 96(2):95-112

Mendi P (2015) Competitive pressure and innovation in vertically differentiated markets. Econ Bull 35(4):2309-2316

Mendi P, Costamagna R (2017) Managing innovation under competitive pressure from informal producers. Technol Forecast Soc Change 114:192-202

Milliou C, Sandonís J (2018) Manufacturer mergers and product variety in vertically related markets. J Ind Compet Trade 18:1-24

Moner-Colonques R, Sempere-Monerris J, Urbano A (2004) Strategic delegation with multiproduct firms. J Econ Manag Strategy 13(3):405-427

Motta M (1993) Endogenous quality choice: price vs quantity competition. J Ind Econ 41(2):113-131

Mussa M, Rosen S (1978) Monopoly and product quality. J Econ Theory 18(2):301-317

Nguyen X, Sgro P, Nabin M (2014) Licensing under vertical product differentiation: price vs. quantity competition. Econ Modell 36:600-606

Ronnen U (1991) Minimum quality standards, fixed costs, and competition. RAND J Econ 22(4):490-504

Shaked A, Sutton J (1982) Relaxing price competition through product differentiation. Rev Econ Stud 49:3-13

Shaked A, Sutton J (1983) Natural oligopolies. Econometrica 51(5):1469-1483

Valletti TM (2000) Minimum quality standards under Cournot competition. J Regul Econ 18(3):235-245

Vetter H (2017) Pricing and market conduct in a vertical relationship. J Econ 121(3):239-253

Vives X (2008) Innovation and Competititive Pressure. J Ind Econ 56(3):419-469

Wang X, Li J (2020) Downstream rivals' competition, bargaining, and welfare. J Econ 131:61-75

Publisher's Note Springer Nature remains neutral with regard to jurisdictional claims in published maps and institutional affiliations. 